\title{
Newborn screening and changing face of inborn errors of metabolism in the United States
}

\author{
Shibani Kanungo, Dilip R. Patel, Mekala Neelakantan, Brinda Ryali \\ Western Michigan University Homer Stryker MD School of Medicine, Kalamazoo, MI, USA \\ Contributions: (I) Conception and design: S Kanungo; (II) Administrative support: S Kanungo; (III) Provision of study materials or patients: S \\ Kanungo; (IV) Collection and assembly of data: S Kanungo; (V) Data analysis and interpretation: S Kanungo; (VI) Manuscript writing: All authors; \\ (VII) Final approval of manuscript: All authors. \\ Correspondence to: Shibani Kanungo, MD, MPH. Department of Pediatric and Adolescent Medicine, Western Michigan University Homer Stryker \\ MD School of Medicine, 1000 Oakland Drive, Kalamazoo, MI 49008, USA. Email: Shibani.Kanungo@med.wmich.edu.
}

\begin{abstract}
Newborn screening (NBS) in the United States helps each year diagnose, 1 in every 320 newborns (12,500 of the 4 million births), with a potentially severe or lethal condition prior to clinical symptoms manifestation. $10 \%$ of these are inborn errors of metabolism (IEM). Coordinated efforts of NBS program, primary care physicians, and metabolic centers can help with pre-symptomatic identification and interventions for such conditions to ameliorate or resolve associated morbidity and mortality. NBS in the United States is a successful public health program to improve short and long term health outcomes for newborns. Federal and State agencies provide the regulatory and funding framework to implement NBS programs, while professional societies provide medical guidelines to help identify and manage such conditions. However, each State independently organizes and administers its own NBS program. This article reviews the common NBS program workflow, federal regulatory framework, uniform screening panel recommendations, the testing processes and ethical considerations involved.
\end{abstract}

Keywords: Newborn screening (NBS); recommended uniform screening panel; dried blood spot test; metabolic disorders

Submitted Nov 07, 2018. Accepted for publication Nov 28, 2018.

doi: 10.21037/atm.2018.11.68

View this article at: http://dx.doi.org/10.21037/atm.2018.11.68

\section{Newborn screening (NBS)-history and regulatory framework}

NBS for inborn errors of metabolism (IEM) disorders in United States started more than 50 years ago, in the 1960s, with detection of a single disorder-phenylketonuria. And, as of July 2018, in all 50 States of the United States, at least 29 of the 35 core conditions listed in the Recommended Universal Screening Panel (RUSP) is screened on every newborn (1-3). NBS programs are organized, governed and administered by respective State Public Health Departments within each State's legislative process and regulatory framework. Metabolic/Biochemical Geneticists practicing in individual States play an advisory role to determine which conditions need to be included in their
State's screening panel and generally follow the RUSP list recommended by the Secretary of U.S. Department of Health and Human Services (DHHS) (1-3).

The Advisory Committee on Heritable Disorders in Newborn and Children (ACHDNC) was established under the Public Health Service Act, Title XI, $\$ 1109$ (42 U.S.C. 300b-10), as amended by the Newborn Screening Saves Lives Reauthorization Act of 2014 (P.L. 113-240) and chartered on May 7, 2015 (1,3-5). The ACHDNC mission is 'to reduce morbidity and mortality in newborns, who have or are at risk for, heritable disorders' $(4,6)$. The ACHDNC provides guidance to the DHHS Secretary in developing NBS policies and practice standards $(4,6)$.

Historically, NBS standardization as current universal screening test got concrete traction with the availability of 
multiplex technologies such as tandem mass spectrometry (MS/MS) or high pressure liquid chromatography (HPLC) in the 1990s (6-8). But, in 2002, the Maternal and Child Health Bureau (MCHB) of the Health Resources and Services Administration (HRSA) of the US DHHS upon commissioning the American College of Medical Genetics (ACMG), led to identification of core panel and secondary targets and current RUSP list. Current IEM disorder list, as of July 2018, includes 9 organic acid disorders, 5 fatty acid oxidation defects, 6 amino acid disorders, 2 inherited enzyme defects, 2 lysosomal storage disorder and 1 peroxisomal disorder. RUSP list of all core and secondary conditions can be found online at https://www. hrsa.gov/sites/default/files/hrsa/advisory-committees/ heritable-disorders/rusp/rusp-uniform-screening-panel. pdf (3). ACMG looked at 81 conditions and based on ACMG criteria of easy identification at 24-48 in asymptomatic newborns; easy to administer test with high sensitivity and specificity; easy and prompt intervention, treatment and management with early diagnosis. And, included only 29 of these as the core conditions in the original RUSP. The Uniform Panel Work Group used a weighted scoring system to identify conditions according to criteria in three main categories: (I) the clinical characteristics of the condition, (II) the screening test, and (III) diagnosis, follow-up, treatment, and management. The Uniform Panel Workgroup also made recommendations for State NBS programs, RUSP process details can be found in the HRSA website (3).

It is fascinating to know that Eunice Kennedy Shriver and Robert Guthrie were both astute and key family advocates for family members with intellectual disability, who along with Robert Macready's initiative in Massachusetts, established the first universal NBS program for Phenylketonuria (PKU) on a state legislative and regulatory framework $(2,9,10)$.

In the early 1960s, PKU screening test was devised by Robert Guthrie $(2,4,7,10,11)$. The basis for the test was that B-2-thienylalanine when added to a culture of Bacillus subtilis, it inhibited bacterial growth. When a blood spot from an infant was added to a culture of Bacillus subtilis and B-2-thienylalanine, the bacteria utilized the phenylalanine from the blood spot, to overcome the B-2-thienylalanine inhibition and grow (12). Overgrowth of Bacillus subtilis beyond a pre-determined normal range would indicate elevated level of phenylalanine in the sample of the blood and therefore PKU (12). This test was often limited by false positive results. At the time, the amount of phenylalanine to be restricted was not established.

Since the invention of the PKU test by Robert Guthrie, 150 million infants in the United States have been screened for a number of inherited metabolic and genetic conditions $(2,10,12)$. By early 1960 , the reasons for infant morbidity and mortality shifted from infectious and nutritional diseases to intellectual disability caused by inherited and genetic disorders (12). In 1962, then President Kennedy established the President's Panel on Mental Retardation (now called intellectual disability) $(2,10,12)$.

In 2007, The Newborn Screening Saves Lives Act (H.R. 3825, S. 1858) amended the Heritable Disorders Program legislation, adding several programs, and further defining ACHDNC activities (5). It was re-authorized in 2014 with additional provisions and an informed consent amendment. The main elements of the act include the following:

(I) Grant funding for:

(i) Educational programs for congenital, genetic and metabolic diseases;

(ii) Training programs in NBS technologies;

(iii) Coordination of follow up care.

(II) Increase public awareness of NBS resources.

(III) Improve and regulate quality NBS laboratory testing processes and procedures.

(IV) Create a national contingency plan in the event of a public health emergency.

(V) Establish Clearinghouse of Newborn Screening Information-Baby's First Test (13).

(VI) Increase ACHDNC roles and duties.

(VII) Rename NICHD's NBS research program as the Hunter Kelly Newborn Screening Research Program; to coordinate and expand NBS research (14) with a goal to increase the number of diagnosable conditions, understand the long-term effects, and to foster development of new treatments.

The Unites States Senate added an amendment to the Newborn Screening Saves Lives Act mandating parent or legal guardian consent to use of the NBS dried blood spot for research using federal funding (5). This requirement only applies to newborn dried blood spots collected after March 17, 2015. Newborn Screening Saves Lives Reauthorization Act (P.L.113-240) was effective March 16, 2015 (5).

NBS, especially for metabolic disorders or IEM is considered as one of the most successful public health achievements (15). More than fifty years ago, in 1960s, NBS started with identifying one 'intoxication' amino acid disorder like PKU, followed by addition of 'other' enzyme 


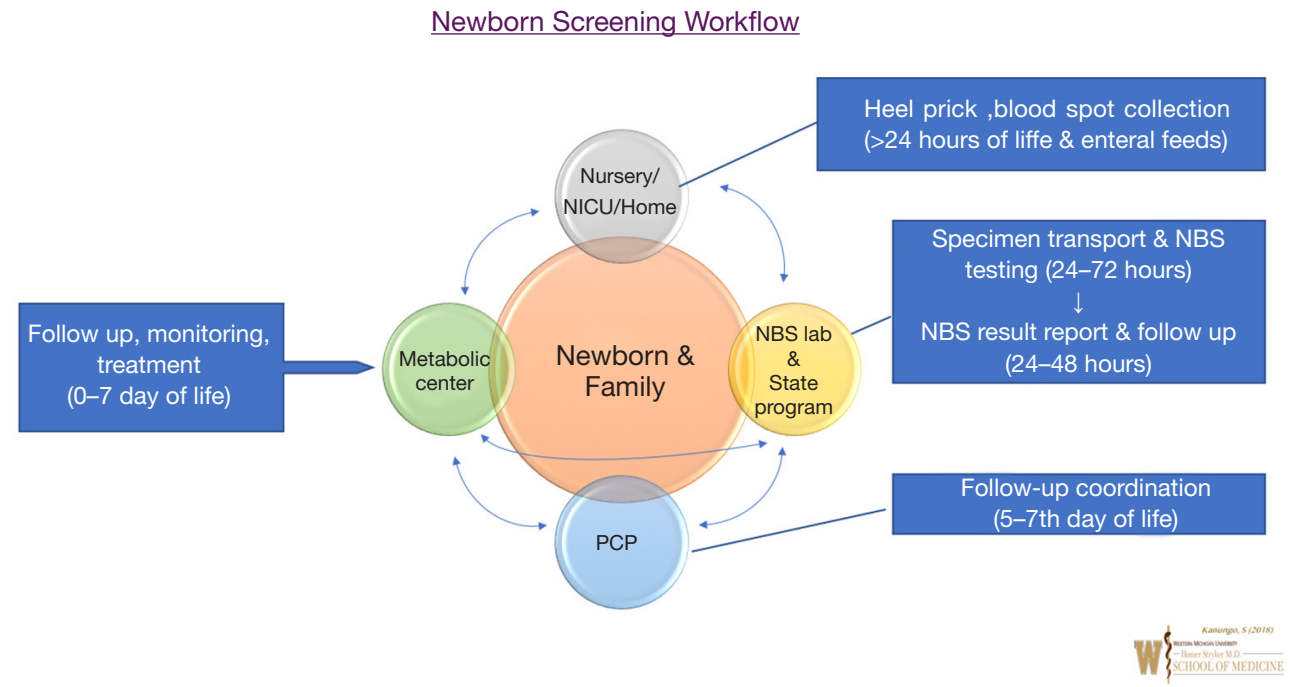

Figure 1 Newborn screening workflow.

defects like Galactosemia and Biotinidase deficiency in the 1980s, followed by in 2000s tandem MS and RUSP - facilitated addition of over 20 disorders to include 'intoxication' and 'energy deficit', i.e., amino acid, organic acid and fatty acid oxidation defects, to addition of 'complex molecules' aka lysosomal storage and peroxisomal disorders in last few years. This public health program concept, based on WHO's Wilson Jungner's 'Principles And Practice of Screening For Disease' criteria included: (I) public health importance of disorder; (II) understanding of natural history of disorder; (III) asymptomatic detection; (IV) early treatment beneficence in outcomes; $(\mathrm{V})$ easy-to-administer test; (VI) low-cost to implement as a screening test; (VII) validity of repeat testing; (VIII) health care access and support for screen positives; (IX) individual and societal benefits outweighing the risks; $(\mathrm{X})$ cost-benefit ratio outweighing above factors to consider it as a public health administered program (16).

Each year, there are close to 4 million infant births in the United States, of which, $99.9 \%$ are screened by the NBS programs $(10,12,17,18)$. In some cases, parents, based on their religious or personal beliefs may opt-out their infant from being screened. Approximately 12,500 newborns each year get a diagnosis of one of the 29 core conditions included in the RUSP; that is 1 out of every 320 newborn screened is diagnosed having one of the 29 core conditions $(10,12,18)$. Of the 125,000 diagnosed; almost $10 \%$ $(1,237$ newborns) of these are diagnosed with an IEMs that are intellectually debilitating or fatal in the newborn period or early infancy (12). This means the previous notion of rare disorder ( 1 in 10,000 or less) does not hold ground as the cumulative incidence of IEMs detected by NBS is 1 in 3,234 (1,237 of 4 million births). Universal screening of all infants allows for the pre-symptomatic detection and treatment of core panel conditions before any clinical signs or symptoms manifest.

\section{The newborn dried blood spot screening workflow}

Newborn Dried Blood Spot (DBS) screening general workflow for IEM or metabolic disorders is shown in Figure 1. In the US, every newborn whether born in a hospital setting or home setting or in NICU, gets a newborn screen typically after 24 hours of birth or prior to hospital discharge. At birth, parents identify a primary care provider (PCP) for their newborn prior to NBS collection.

The ideal circumstance to obtain newborn dried blood spot screening is after initiation of oral or enteral feeding. NBS Dried Blood spot cards undergo disorder detection utilizing multiplex technologies such as MS/MS at a State Public Health Laboratory or State contracted biochemical genetic laboratory in 24-72 hours after collection. Results report is generated from State Newborn Screening Follow up Program ideally by day 7 of life of a newborn; and provided to individual newborn's PCP. If a positive screen is identified, NBS state program notifies the State designated Metabolic Centers and the PCP for evaluation and diagnostic testing of the newborn.

In addition to confirmatory diagnostic testing, treatment 
management may be initiated by Metabolic Physicians (Biochemical Geneticist) and metabolic center team. If a screen is inconclusive or there are specimen integrity or performance issues, the birthing hospital and PCP are notified for NBS DBS specimen recollection. Birthing Hospitals can coordinate with PCP or request families to return to the hospital laboratory to obtain NBS DBS recollection. After diagnostic confirmation, if a positive screen is identified as a case, the metabolic center notifies the case detection to the State NBS program and continues follow-up and treatment plan of identified IEM. This workflow can get more complicated for infants admitted in NICU but a State specific policy and individual hospital NICU policy can ensure NBS integrity and timeliness. Ideally for NICU infants, NBS should be obtained after 24hours of enteral or oral feeds and definitely prior to discharge with a scheduled close follow-up with PCP. Though, upon clinical suspicion of an IEM, any NICU team can work with their local Metabolic Team in diagnostic evaluation and IEM management, regardless of NBS result report.

This workflow coordination with multiple stakeholders as shown in Figure 1 can be complicated with possibility of human error. Any incongruence in such workflow can lead to a lapse in NBS of a newborn with dire consequences such as death or disability. Apart from State NBS program, identification of lapsed NBS related workflow may be missing at local birthing hospital or PCP. Especially, if a PCP identified in the birthing hospital by the family is different from the PCP actually followed by the family or if the family moves to another area or State.

Brain damage in a baby in Wisconsin led to a nationwide investigative Journal Sentinel Watch Dog report in 2013 noting initial NBS timeliness issues across various hospitals in various states (19). For example, in 2012, in the State of Pennsylvania, 27 hospitals had $10-65 \%$ of their NBS specimen taking more than 5 days to reach the NBS testing lab. That means 4,670 newborns of the total 140,873 births potentially could have had long term disability or permanent brain damage or died of an treatable IEM $(20,21)$. More research into factors affecting Quality Indicators (QI) on NBS performance ultimately seemed to be individual birthing hospital or hospital system NBS QI dependent [SK unpublished data, (22)].

Multiple factors have been shown to be effective in addressing the potential barriers to NBS QI for hospital systems. These include: (I) systems reengineering at local birthing hospital or hospital system, (II) using electronic health record (EHR) system, (III) system wide educational training of nursing and laboratory services staff, (IV) identification of precise staff role in the workflow, (V) responsibilities and coordination between nursing and laboratory services, and (VI) follow-up coordination for repeat specimen recollection with every newborn's family, and (VII) use of Mobile Van laboratory or home-based NBS DBS collection services. Improvement was noted in timeliness of initial and repeat NBS (birth to collection), transportation (collection to arrival at NBS Lab), follow-up (NBS result reporting to primary care physicians), NBS test recollection and case identification [SK unpublished data, (22)].

\section{Public NBS resources}

A number of public, private and academic sector resources at the local, state, and Federal level are accessible to lay public as well as professionals, via the internet websites from which, most of the following information is obtained $(5,8,10,13,14,17,18,23-26)$.

\section{NBS Technical assistance and Evaluation Program (NewSTEPs)}

NewSTEPs funded by HRSA provides resources to state NBS programs to improve NBS quality and performance. NewSTEPs is created under a cooperative agreement with the US DHHS, HRSA, MCHB with the Newborn Screening Saves Lives Act and its 2014 Reauthorization provisions that authorize federal action by HRSA on Heritable Disorders (8).

The NewSTEPs program collects and houses detailed information on each State/US territory NBS programs and accessible online. The NewSTEPs program works collaboratively with other national programs in data collection and report dissemination. The data include individual state profiles (description of each state program including program hours, fees, and disorders screened), Quality Indicators (metrics of program performance encompassing screening accuracy and timeliness) and NBS public health surveillance case definitions. The Association of Public Health Laboratories (APHL) collaborates with the Colorado School of Public Health (ColoradoSPH) to implement NewSTEPs (8). Its goal is to improve outcomes for newborns by facilitating NBS initiatives and programmatic outcomes to improve the overall quality of 
the NBS system.

\section{National Newborn Screening and Genetics Resource Center (NNSGRC)}

NNSGRC is sponsored by the University of Texas Health Science Center at San Antonio (UTHSCSA), Department of Pediatrics (23). The NNSGRC assists in coordinating NBS and genetics activities as a national resource center. The NNSGRC serves as a platform to provide a forum for interaction between consumers, health care professionals, researchers, organizations, and policy makers in refining and developing public health NBS and genetics programs. NNSGRC assists states enhance their NBS activities through (I) technical assistance reviews and (II) integration of new developments in genetics, health promotion and disease prevention into the public health system. NNSGRC provides annual reports on the state and regional NBS programs, and fosters a national dialogue on emerging NBS topics. It also supports development and implementation of innovative NBS projects.

\section{Eunice Kennedy Shriver National Institute of Child Health and Human Development (NICHD)}

NICHD role in IEM NBS helps (I) identify new conditions for inclusion; (II) identify and improve lab testing methodology; (III) evaluate treatments efficacy and outcomes; (IV) consumer and healthcare provider education; (V) coordination and regulatory efforts for the state NBS programs; and (VI) sponsor NBS research and training programs (27).

\section{Baby's First Test}

Baby's First Test, a clearinghouse for NBS information, provides NBS educational including local, State and National support resources for families with NBS IEM disorders. Baby's First Test also provides a platform for public comments on NBS (13). NBS Saves Lives Act passed in 2008 and Newborn Screening Saves Lives Reauthorization Act passed in 2014 (5) include provisions for clearinghouse roles.

In addition, Baby's First Test engages in dialogue about NBS among various stakeholders including health professionals, public health officials, policy makers, and industry.

\section{Ethical considerations for NBS}

Since the very beginning of NBS programs, there have been ongoing debate about various ethical issues (2,4,26,28-31).

Ethics of NBS for any condition has mainly revolved around the basic tenets of Wilson and Junger criteria as described above. Though one could argue that the fundamental ethical principles of 'Nonmaleficence' and 'Justice' are non-debatable in NBS, 'Respect for Autonomy' or 'Beneficence' can be debated.

'Respect for Autonomy' is most tested when a family gets a call from PCP or birthing hospital for a recollection of NBS DBS or of a positive screen. Often families hear about the NBS test done at that time (32). NBS is included as opt-in for all newborns under individual State's legislative, public health regulatory framework with an option to opt-out, if a family chooses to do so for personal or religious reasons. But, an option to opt-out requires a written notification to birthing facility and often such a choice is not usually discussed at the birthing hospital (SK unpublished data).

'Beneficence' as tenet includes NBS intent of doing good by the patient. However, the anxiety, costs associated with diagnostic confirmation odyssey with false positive and inconclusive screens or extent of treatment and procedures for clinically asymptomatic infants or carriers, can create a "vulnerable child" or establishment of "pre-existing condition" for medical insurance. This may be contrary to the underlying intent of beneficence (32-36).

Post screening NBS leftover specimen are another area of debate with researchers seeing a fertile specimen repository for genetic research with equally strong notions about 'Respect for Autonomy' (32,36-39).

'Beneficence' is also debated when a newborns is identified with an IEM and requires metabolic nutrition to prevent associated long-term mortality and morbidity. Legislative processes on federal and state level are yet to act to address treatment needs of current IEM disorders screened by NBS for 50 years like phenylketonuria (40).

Another area of 'Beneficence' debate is the paucity of IEM trained and board certified biochemical geneticist; who are responsible for the majority of the disorders identified by NBS (41); thus placing undue burden on PCP, who often feel inept as intermediary for NBS follow-up as routine practice $(42,43)$.

The issues of resource allocation, availability of data and evidence, individual and parental rights and advances in technology are other areas of NBS ethical debate (26,28-31). 


\section{Resource allocation}

The cost associated with population wide NBS programs is an important consideration in the ethics debate as it relates to the principle of justice. Because early identification of life threatening disease allows for immediate initiation of treatment, with potential for avoiding death, it can be argued that cost should not be a consideration. On the other hand, when available resources are finite, one must also consider the opportunity cost - the funds could have been used more appropriately on prevention and treatment of other more prevalent health conditions. One must weigh the benefits against the costs in the allocation of resources to different public health programs.

Equitable distribution of benefits from NBS is also an important consideration. In United States, each state NBS list of IEM disorders, in addition to the 29 core conditions in RUSP, vary from state to state. This may result in an unfair distribution of benefits to the infant and the family, depending up on the state in which infant is born. There may also be variability in the available follow up and treatment services between states. It is generally agreed by most experts involved in the NBS programs that the distribution of the costs and benefits is arbitrary and fails to meet a reasonable standard of equity and fairness. A major objective of professional organizations aims to reduce or eliminate variability in test panels and services in different states.

\section{Availability of data and evidence}

Availability of comprehensive data and its analysis are essential to inform decisions about resource allocations and assess benefits of NBS programs. On the other hand, one could argue that given the rarity of the inherited errors of metabolism and difficulty in clinical identification, NBS is the only reasonable approach to early detection and treatment for such conditions.

Gathering and evaluation of evidence to guide policy decisions also requires use of resources. This raises the question of what should be considered sufficient evidence to guide any decisions. Some have advocated that resources could be better used for screening than trying to gather evidence. After almost 12 years of Universal NBS in all fifty states in the US; any data is only the last available 2006 data on NBS disorder detection in form a 2009 National NBS incidence report (11).

\section{Individual and parental rights}

Individuals have the right to make their own health-related decisions, including how their health-related information is used. In the case of NBS, the test samples are stored for future use for possible additional testing at a later date or research. Because, parents or legal guardians generally make decisions on behalf of their minor children, parental informed consent is the ethical standard. In the United States, NBS is mandatory, which is contrary to the ethical standard of informed consent. Such a departure from ethical standard has been justified on the basis of greater good for the family and society as a result of early detection and treatment of genetic conditions.

\section{Advances in technology}

With advances in technology, the cost of genome sequencing has continued to decline and has reached levels comparable to other standard laboratory tests in current use. Genome sequencing can be used for NBS and can provide comprehensive genetic information about the newborn that will inform future medical decisions. However, this raises some important questions about its justification, individual rights, and costs and benefits to the individual or the society. Before genomic sequencing can be applied to NBS a careful consideration of potential risks and benefits to the individual and society should be considered. Though, this could be rich soil for researchers on potential rare diseases; the use of public health resources and taxpayers coffer contribution can raise question the additional need for research funding using public health infrastructure when research based funding mechanisms are well delineated by National Institute of Health (44).

\section{Conclusions}

NBS programs have been well established in the United States with a track record of significant individual, societal and public health benefits. However, debate continues around some important ethical issues, especially in terms of rapid advances in technology, such as potential application of genomic sequencing to NBS. Considerable progress has been made in developing uniform standards across states in the administration and ongoing monitoring of NBS programs. 


\section{Thoughts for future direction}

Within past few years biomedical technology has advanced at a rapid pace, allowing for novel ways to screen for IEM. On the other hand, research based evidence in the field of NBS has been lagging, thus requiring integration of expert consensus in the development of NBS guidelines and standards. Based on available research, in combination with expert consensus, 35 primary and 26 secondary conditions have been currently recommended by RUSP for inclusion in NBS programs. Of these, 25 primary and 24 secondary conditions are IEM or metabolic disorders (3).

With the ability to screen for and inclusion of more conditions for NBS, ongoing public and professional education is essential. In addition, the development of appropriate infrastructure in needed for life-span follow up and management of children and adults diagnosed with IEM.

To improve outcomes these children with identified conditions require a metabolic medical home in setting integrated behavioral health model with nutrition, psychology, social work/genetic counseling support. Current models of one or two metabolic centers per state in major cities, with concentration of multiple metabolic expertise and resources fail to address the basic tenet of 'access to care' for families already burdened with needs of devastating IEM disorders. Metabolic genetics expertise though an intense \& niche field of medicine, is not viewed as a revenue generating clinical practice, and allied health support to provide standard of care are often unavailable in non-metabolic center academic or hospital system setting. Since NBS is a public health program, access to care of all newborns in a state and, perhaps as a metabolic medical home model in every hospital or academic medical education system can be advocated on a legislative and regulatory framework to maximize "beneficence".

\section{Acknowledgements}

None.

\section{Footnote}

Conflicts of Interest: The authors have no conflicts of interest to declare.

\section{References}

1. Recommended Uniform Screening Panel। Official web site of the U.S. Health Resources \&amp; Services Administration. [cited 2018 Oct 16]. Available online: https://www.hrsa.gov/advisory-committees/heritabledisorders/rusp/index.html

2. Brief History of Newborn Screening I NICHD - Eunice Kennedy Shriver National Institute of Child Health and Human Development. [cited 2018 Nov 5]. Available online: https://www.nichd.nih.gov/health/topics/newborn/ conditioninfo/history

3. Recommended Uniform Screening Panel. Available online: https://www.hrsa.gov/sites/default/files/hrsa/advisorycommittees/heritable-disorders/rusp/rusp-uniformscreening-panel.pdf

4. Secretary's Advisory Committee on Heritable Disorders in Newborns and Children 2011 Annual Report to Congress. [cited 2018 Nov 5]. Available online: https:// www.hrsa.gov/advisory-committees/heritable-disorders/ recommendations-reports/reports/index.html

5. H.R.1281 - 113th Congress (2013-2014): Newborn Screening Saves Lives Reauthorization Act of 2014. [cited 2018 Nov 5]. Available online: https://www.congress.gov/ bill/113th-congress/house-bill/1281/text

6. Millington DS, Kodo N, Roe CR et al. Tandem mass spectrometry: A new method for acylcarnitine profiling with potential for neonatal screening for inborn errors of metabolism. J Inherit Metab Dis 1990;13:321-4.

7. Centers for Disease Control and Prevention (CDC). Good laboratory practices for biochemical genetic testing and newborn screening for inherited metabolic disorders. MMWR Recomm Rep 2012;61:1-44.

8. NewSTEPs. [cited 2018 Oct 27]. Available online: https:// www.newsteps.org/about

9. Levy HL. Historical Perspectives: Newborn Metabolic Screening. NeoReviews 2005;6:e57-60.

10. Ten Great Public Health Achievements --- United States, 2001--2010. [cited 2018 Nov 5]. Available online: https:// www.cdc.gov/mmwr/preview/mmwrhtml/mm6019a5.htm

11. Newborn Screening Reports and Publications I National Newborn Screening and Global Resource Center. [cited 2018 Oct 27]. Available online: Http:// genes-r-us.uthscsa.edu/sites/genes-r-us/files/resources/ genetics/2006datareport.pdf

12. CDC Grand Rounds: Newborn Screening and Improved Outcomes. [cited 2018 Nov 5]. Available online: https:// 
www.cdc.gov/mmwr/preview/mmwrhtml/mm6121a2.htm

13. Baby's First Test I Newborn Screening I Baby Health [Internet]. [cited 2018 Oct 27]. Available online: https:// www.babysfirsttest.org/

14. The NICHD and Newborn Screening: A New Era I NICHD - Eunice Kennedy Shriver National Institute of Child Health and Human Development. [cited 2018 Nov 6]. Available from: https://www.nichd.nih.gov/newsroom/ resources/spotlight/101309-newborn-screening

15. Wilcken B, Wiley V. Fifty years of newborn screening. J Paediatr Child Health 2015;51:103-7.

16. Wilson JM, Jungner O. The Principles of screening for disease. Available online: http://apps.who.int/iris/ bitstream/10665/208882/1/WHO_PA_66.7_eng.pdf

17. Hamilton BE, Martin JA, Osterman MJK, et al. National Vital Statistics Reports Births : Final Data for 2013. Natl Vital Stat Reports 2015;64:1-104.

18. CDC - Newborn Screening Portal. [cited 2018 Nov 6]. Available from: https://www.cdc.gov/newbornscreening/

19. Deadly Delays Journal Snetinel Watch Dog report. [cited 2018 Oct 22]. Available online: http://archive.jsonline. com/watchdog/Deadly-Delays-Watchdog-Reportnewborn-screening-program-231927171.html

20. Newborn screening programs, state by state. [cited 2018 Oct 22]. Available online: http://archive.jsonline.com/ watchdog/deadly-delays-newborn-screening-programsstate-by-state-228834411.html\#!/pennsylvania/

21. Birth Statistics PA.GOV by year. [cited 2018 Oct 22]. Available online: https:/www.health.pa.gov/topics/ HealthStatistics/VitalStatistics/BirthStatistics/Pages/ birth-statistics.aspx

22. S Kanungo NBS performance. APHA 2016 Annual Meeting \&amp; Expo (Oct. 29 - Nov. 2, 2016). [cited 2018 Oct 22]. Available online: https://apha.confex.com/ apha/144am/meetingapp.cgi/Search/0?sort=Relevance\&si ze $=10 \&$ page $=1$ \& searchterm $=$ kanungo

23. National Newborn Screening and Global Resource Center. [cited 2018 Oct 27]. Available online: http:// genes-r-us.uthscsa.edu/

24. Newborn Screening - The Hastings Center. [cited 2018 Nov 6]. Available online: https://www.thehastingscenter. org/briefingbook/newborn-screening/

25. ACMG ACT Sheets and Algorithms. [cited 2018 Nov 6]. Available online: http://www.acmg.net/ ACMG/Medical-Genetics-Practice-Resources/ACT_ Sheets_and_Algorithms/ACMG/Medical-GeneticsPractice-Resources/ACT_Sheets_and_Algorithms. aspx?hkey=9d6bce5a-182e-42a6-84a5-b2d88240c508
26. Newborn Screening Fact Sheet - National Human Genome Research Institute (NHGRI). [cited 2018 Nov 6]. Available online: https://www.genome.gov/27556918/ newborn-screening-fact-sheet/

27. Newborn Screening I NICHD - Eunice Kennedy Shriver National Institute of Child Health and Human Development. [cited 2018 Oct 27]. Available online: https://www.nichd.nih.gov/health/topics/newborn

28. The President's Council on Bioethics. The Changing Moral Focus of Newborn Screening: An Ethical Analysis by the President's Council on Bioethics (Chapter 4: Newborn Screening: Mandatory, Elective, or Both?). [cited 2018 Nov 6]. Available online: https://bioethicsarchive. georgetown.edu/pcbe/reports/newborn_screening/ chapter4.html

29. Goldenberg AJ, Sharp RR. The ethical hazards and programmatic challenges of genomic newborn screening. JAMA 2012;307:461-2.

30. Tarini BA, Goldenberg AJ. Ethical issues with newborn screening in the genomics era. Annu Rev Genomics Hum Genet 2012;13:381-93.

31. van der Burg S, Oerlemans A. Fostering caring relationships: Suggestions to rethink liberal perspectives on the ethics of newborn screening. Bioethics 2018;32:171-83.

32. Timmermans S, Buchbinder M. Saving babies? The consequences of newborn genetic screening. Chicago: The University of Chicago Press Books, 2015.

33. Ross LF. Ethical and Policy Issues in Newborn Screening of Children for Neurologic and Developmental Disorders. Pediatr Clin North Am 2015;62:787-98.

34. Wasserstein MP, Andriola M, Arnold G, et al. Clinical outcomes of children with abnormal newborn screening results for Krabbe disease in New York State. Genet Med 2016;18:1235-43.

35. Lantos JD. Dangerous and expensive screening and treatment for rare childhood diseases: the case of Krabbe disease. Dev Disabil Res Rev 2011;17:15-8.

36. Gupta S. Screening: Baby's first test. Nature 2016;537:S162-4.

37. Committee on Bioethics, Committee on Genetics, American College of Medical Genetics, et al. Ethical and Policy Issues in Genetic Testing and Screening of Children. Pediatrics 2013;131:620-2.

38. Yan $W$. New consent requirements for newborn screening raise concerns. Nat Med 2015;21:542-3.

39. Federal lawsuit claims Michigan stole blood of newborn babies. [cited 2018 Oct 27]. Available online: https:// 
www.mlive.com/news/index.ssf/2018/04/federal_lawsuit_ claims_michiga.html

40. The Society for Inherited Metabolic Disorders. Policy Statement: Coverage for Medical Foods. [cited 2018 Oct 30]. Available online: https://www.simd.org/Statements/ MedicalFoods2016.htm

41. Summar M. Save the biochemical geneticists! Mol Genet Metab 2014;113:2-3.

Cite this article as: Kanungo S, Patel DR, Neelakantan M, Ryali B. Newborn screening and changing face of inborn errors of metabolism in the United States. Ann Transl Med 2018;6(24):468. doi: 10.21037/atm.2018.11.68
42. Summar M, Kirmse B, Monaco J. Mind the Gap. Mol Genet Metab 2014;113:1.

43. McCabe ER. Newborn screening: A complex system that requires a culture of safety. Mol Genet Metab 2014;113:6-7.

44. Rare Diseases Clinical Research Network. [cited 2018 Oct 30]. Available online: https://www. rarediseasesnetwork.org/ 